\title{
DG Penetration for Household Nonlinear Loads as a Solution to PQ Enrichment
}

\author{
S. Poongothai ${ }^{1}$, and S. Srinath ${ }^{2}$
}

\begin{abstract}
In the recent years, power quality has become a very predominant issue for research, contributing a majority from residential loads. As the new technologies in house hold appliances are developed with solid state switching devices, it introduces nonlinearity into the system causing harmonics, voltage fluctuation, poor power factor etc. This can be eliminated to a remarkable extent by using a standalone solar system with battery backup to supply lighting and frequently used essential low power devices. The system can be implemented without much compromise in the installation cost. Penetration of Distributed Generation(DG) into the system improves the reliability of power supply, possibly at a lower cost over a period of time. The effectiveness of the use of standalone DG for household applications is discussed in this paper with a view to decrease the Total Harmonic Distortion on the line when they are operated with AC supply. The simulation is carried out using MATLAB/Simulink and the results are verified through experimental findings.
\end{abstract}

Keywords- Distributed Generation, Nonlinear load, Power Quality, Total harmonic Distortion, Light Emitting Diode, Compact Fluorescent Lamp, Brushless DC Motor

\section{INTRODUCTION}

$\mathrm{N}$ OW a days there are various types of house hold appliances like personal computer, laptop charger, LED, CFL lamps etc. which work on low voltage dc supply. The number of electrical appliances used in a typical household has grown year by year rapidly. All this type of nonlinear loads introduces harmonics into the system. Earlier, harmonics produced by domestic loads in a grid are ignored because of very low disturbances. But these new loads becoming advanced and increasing in number in the past few years. However significant number of such devices and large number of household will have a negative influences causing distortion, dips and harmonics in electricity network [1][2]. The impact on voltage distortion by this large electronic load have been studied in [6].

Harmonics are existing from the earlier days of industry and still are caused by the nonlinear magnetizing impedances of transformers, reactors, fluorescent lamp ballasts, etc.

S. Poongothai ${ }^{1}$, Assistant Professor ${ }^{1}$ is with the Department of Electrical and Electronics Engineering, Velammal Engineering College, Chennai, Tamilnadu, India (poongothai.eee@velammal.edu.in.)

S. Srinath ${ }^{2}$, Associate Professor ${ }^{2}$ is with the Department of Electrical and Electronics Engineering, Velammal Engineering College, Chennai, Tamilnadu, India (drsrinath.eee@ velammal.edu.in.)
In addition, power electronic devices have become abundant today and because of their capabilities for precise process control and energy savings benefits [3][7].

\section{DISTRIBUTED GENERATION}

Distributed Generation (DG) employs smaller-size generators. DG can enhance the generation capacity of a power system without having an adverse impact on the environment. The electricity is usually generated by lowemission technology like wind, Solar PV, Fuel cells etc. Utilization of DG is advantageous due to their natural contributions to reducing greenhouse gas emission and alleviating other environmental problems. These are distributed through the power system but are concentrated mainly closer to the loads. [13]

Compared to traditional large power plants, DG system has the features of low investment costs, covering less and the short construction period. As DG systems are built near the load center, without building costly power transmission network and substations, the power can be transmitted. Its transmission distribution loss is low, and it can decrease the huge investment and power loss due to long-distance transmission DG systems are independent. In case of power grid failure, DG can guarantee for Safe and Reliable Power Supply [9].

The customers get the benefit of backup generation improving the reliability of the power supply, possibly at a lower cost. Installation cost is substantial. However once installed the running cost is negligible due to the availability of abundance sunlight free of cost. They need supplementary source such as battery or flywheel storage. Therefore, there is a growing interest towards a distributed generation (DG) paradigm to provide small-scale generation opportunities close to consumer sites [8].

\section{GRID INTEGRATION OF SOLAR PhOtOVOLtAIC SYSTEM - PQ ISSUES}

Grid integration of solar photovoltaic is being carried through inverter. This Inverter connection can lead to harmonics and voltage flicker in distribution system. Long term performance of grid integrated PV systems shows a remarkable degradation of efficiency due to the variation of source and performance of inverter [10]. These power electronic converters, together with the operation of nonlinear appliances, inject harmonics to the grid. In addition, the 
voltage fluctuation due to irradiation, cloud cover or shading effects could make the PV system unstable in terms of grid connection. Therefore, this needs to be considered in the controller design for the inverter [11] [12]. Therefore, the overall performance of grid integrated solar photovoltaic system including PV modules, inverter, filters.

Injection of the DG with different voltage level into an electrical power grid can affect the voltage quality. Depending on characteristics of the network and DG various protection problem can arise namely false tripping of feeders, unwanted islanding, etc. In grid integrated PV system, a special care should be taken during maintenance period.

Many remote and rural areas are far from the power grid, and it is difficult to supply from the power grid. Therefore, it may be an optimal way to make use of the Stand-alone System applying solar power generation. Recent trends in small-scale distributed generation, particularly drastic price reductions of photovoltaic (PV) systems, will result in high penetration levels.

\section{StANDALONE PV SYSTEM}

Standalone photo voltaic systems functions independent of the electric grid hence the stand alone PV system. It is also called as off grid PV system as it involves no interaction with the utility grid. Many photo voltaic systems operate in standalone mode. Standalone PV system for low power DC applications consists Photovoltaic cells, charge controller and battery banks. The battery bank is designed in such a way to meet the load demands irrespective of the solar irradiance. Without the battery, the system would be unable to meet the load demands outside daylight.

In standalone PV system charge controller is a control element that manages the energy flow to PV system, batteries and loads by collecting information on the battery voltage and knowing the maximum and minimum values acceptable for the battery voltage. Now a days plenty of charge controllers available in market itself.

PWM charge controller became industry standard because of its high performance and cost effectiveness. It slowly lowers the amount of power applied to the batteries as the batteries get closer and closer to fully charged. Maximum Power Point Tracking (MPPT) controllers are more power efficient compared to other two charge controllers. They match the output of the solar panels to the battery voltage to ensure maximum charge (amps). But MPPT's are more expensive and larger in size compared to PWM controller.

\section{MEASUREMENT OF THD}

The presence of harmonics in electrical systems means that current and voltage are distorted and deviate from sinusoidal waveforms [4][5]. The active power $\mathrm{P}[\mathrm{kW}]$ is the arithmetic mean value of the known function in equation (1).

$$
P=\frac{1}{T} \int_{0}^{t} v(t) \cdot i(t)
$$

The apparent power $\mathrm{S}[\mathrm{kVA}]$ is the peak value of the power function in equation (2) and present product of effective voltage and current values.

$$
\mathrm{S}=\mathrm{VI}
$$

Assuming ideal sinusoidal form of voltage and current signals the active Power is

$$
\begin{gathered}
\text { VI } \cos \varphi=\mathrm{P} . \\
\text { Power Factor }=\cos \varphi=\frac{P}{V I}
\end{gathered}
$$

The measurements follow IEEE standard 1459/2010, IEEE standard definitions for the measurement of electric power qualities under sinusoidal, Non-sinusoidal, Balanced, or unbalanced condition. The total harmonic distortion of the voltage is defined as:

$$
T H D v=\frac{V_{H}}{V_{1}}=\sqrt{\left(\frac{V^{2}}{V_{1}^{2}}\right)-1}
$$

The total harmonic distortion of the current is defined as:

$$
T H D i=\frac{I_{H}}{I_{1}}=\sqrt{\left(\frac{I^{2}}{I_{1}^{2}}\right)-1}
$$

\section{Simulation Model}

Simulation is carried out using MATLAB/Simulink with few residential low power DC appliances with solar photovoltaic as input. The simulation model shown in Fig.1 includes low power devices used in the present scenario to provide significant amount of energy savings in comparison with the traditional solution with a cost compromise in the view of power quality. Two loads via a LED lamp and a brushless DC motor are used in the simulation and named as load1 and load 2.The simulation results are presented in the proceeding section along with the experimental results.

A maximum power point (MPP) tracker is designed by the combination of perturb and observe method, which triggers the duty cycle of the DC/DC interleaved boost converter. By changing the duty cycle of converter, the PV panel is made to deliver the maximum power at that irradiance to the load. The MATLAB/Simulink model of perturb and observe method to track maximum power output, along with a DC/DC converter is shown in Fig.1.



Fig. 1 Simulation model of the proposed system

\section{EXPERIMENTAL SETUP}

In order to verify the effectiveness of the proposed standalone system an experimental setup has been built up with low power appliances with ac and dc supply. The power quality analyzer has been used for measurement of THD. The measurement has been conducted on low power household 
appliances including a mobile charging unit, a LED lamp, a Laptop charger and a Printer as shown in Fig.2. The experimental waveforms are taken using a 4 channel Agilent DSO-X3014A and AC/DC current probe. The current is expressed in terms of voltage on a scale of $100 \mathrm{mV} / \mathrm{A}$.

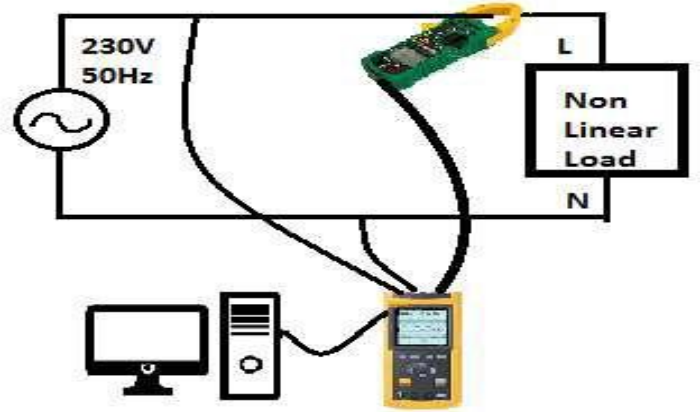

Fig. 2 AC Experimental Setup

For DC standalone system a $12 \mathrm{~V}$ PV panel is connected to the same low power appliances as discussed above through a charge controller and a battery setup as shown in Fig.3.

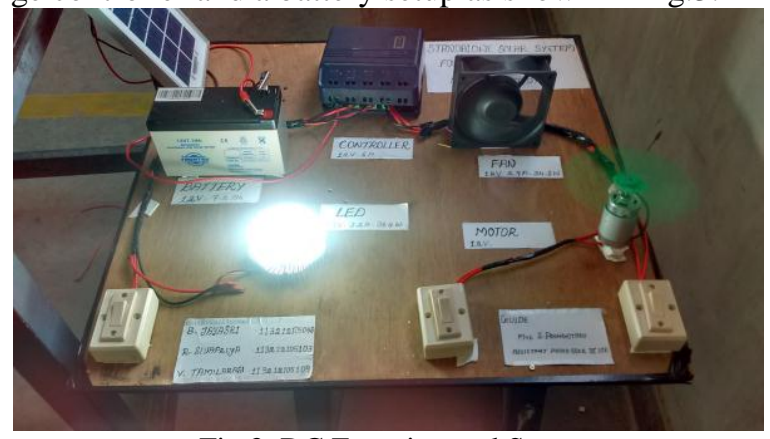

Fig 3. DC Experimental Setup

Ratings of the appliances used in measurement are shown in Table 1. The appliances considered being similar for both the system.

TABLE I

ELECTRICAL RATINGS OF APPLIANCES FOR MEASUREMENT

\begin{tabular}{|c|c|c|c|}
\hline S.No & Appliances & AC Rating & DC Rating \\
\hline \multirow{4}{*}{ I } & LED Lamp & \multicolumn{2}{|c|}{} \\
\cline { 2 - 4 } & Wattage & $7 \mathrm{~W}$ & $8 \mathrm{~W}$ \\
\cline { 2 - 4 } & Output power & $100 \mathrm{~W} / 900 \mathrm{~W}$ & $40 \mathrm{~W}$ \\
\hline \multirow{4}{*}{ II } & Mobile charger & \multicolumn{2}{|c|}{} \\
\cline { 2 - 4 } & Current & $350 \mathrm{~mA}$ & $900 \mathrm{~mA}$ \\
\cline { 2 - 4 } & Input voltage & $230 \mathrm{~V}$ & $12 \mathrm{~V}$ \\
\cline { 2 - 4 } & Output voltage & $5 \mathrm{~V}$ & $5 \mathrm{~V}$ \\
\hline III & Laptop charger & \multicolumn{2}{|c|}{} \\
\cline { 2 - 4 } & Wattage & $65 \mathrm{~W}$ & $65 \mathrm{~W}$ \\
\cline { 2 - 4 } & Input voltage & $230 \mathrm{~V}$ & $12 \mathrm{~V}$ \\
\cline { 2 - 4 } & Output voltage & $19.5 \mathrm{~V}$ & $19.5 \mathrm{~V}$ \\
\cline { 2 - 4 } & Current & $3.3 \mathrm{~A}$ & $3.3 \mathrm{~A}$ \\
\hline IV & Printer & $2.9 \mathrm{~A}$ & $2.9 \mathrm{~A}$ \\
\cline { 2 - 4 } & Current & $230 \mathrm{~V}$ & $12 \mathrm{~V}$ \\
\cline { 2 - 4 } & Input voltage & $12 \mathrm{~V}$ & $12 \mathrm{~V}$ \\
\cline { 2 - 4 } & Output voltage & \multicolumn{2}{|c}{} \\
\hline
\end{tabular}

\section{EXPERIMENTAL RESULTS}

\section{A. LED Lamp}

The most common replacement for incandescent lamps is Compact Fluorescent Lamps(CFL). The next stage for replacement of CFL is LED. The harmonic distortion due to LED has been measured and furnished as shown in Fig 4 \& Fig.5.

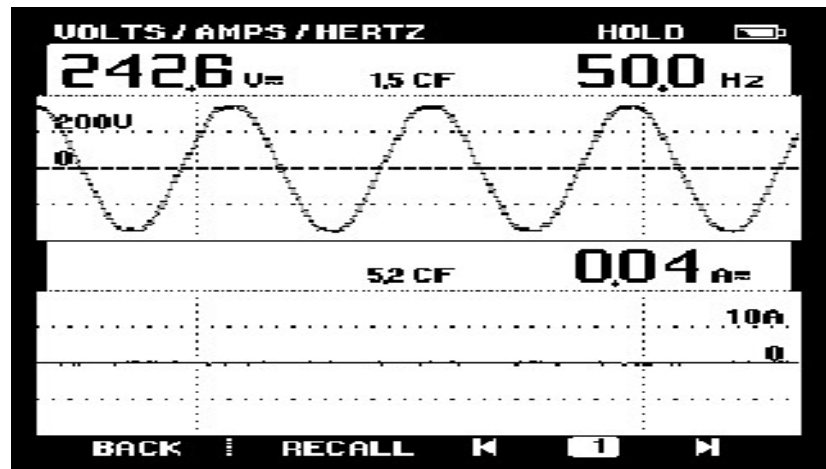

Fig 4. Supply voltage and current waveform for LED (AC System)

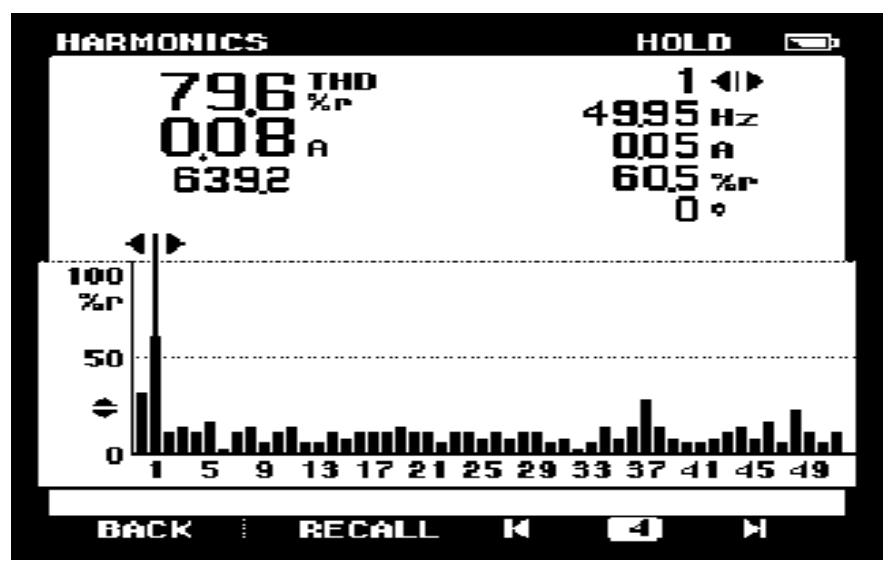

Fig. 5 Harmonic Distortion in LED

Fig.4 \& Fig.5 depicts the hardware results when ac supply is used. It can be noticed that the effect of harmonics and inter harmonics for device LED are significant up to the order of 50th and all odd as well as even harmonics are dominant. The total harmonic distortion is up to $79.6 \%$.

The simulation and experimental results for the proposed standalone DC system has been presented in Fig.6 \& Fig.7.It can be seen that the system works better than with AC mainly from the aspect of injecting nonlinear behavior in voltage and current into the system.

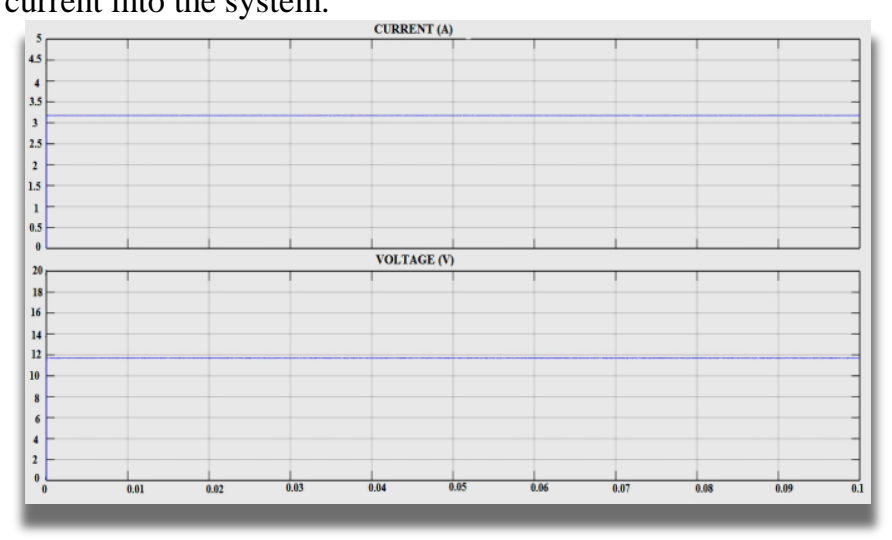

Fig. 6 Simulation Output Waveform of Load1(LED) 


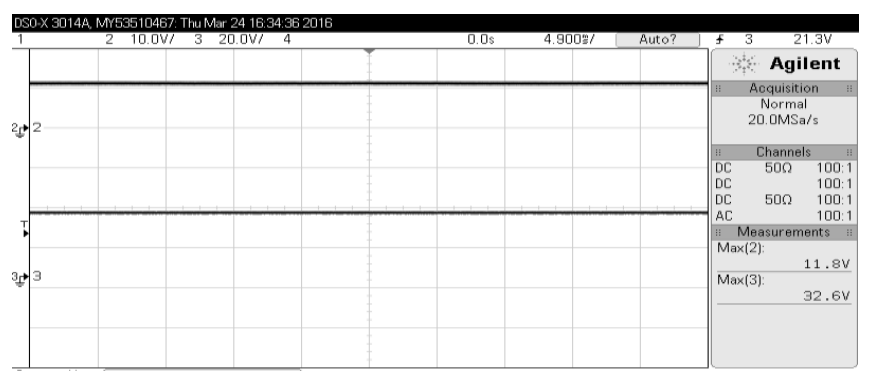

Fig. 7 Supply voltage and current waveform for LED (Standalone DC System)

\section{B. Mobile Charger}

The small size makes it challenging to make an efficient, high-quality charger, while the commoditization of chargers and the demand for low prices pressurize the manufacturers to make the circuit as simple as possible and exclude expensive components, even if the power quality is worse. The source voltage, current and THD when AC system is in use are shown in Fig.8 and Fig.9. It can be noticed that the effect of harmonics for device cell phone charger are significant up to the order of $50^{\text {th }}$ and all odd harmonics $3^{\text {rd }}, 5^{\text {th }}, 9^{\text {th }}, 11^{\text {th }}, 13^{\text {th }}$ and $41^{\text {th }}$ harmonics are dominant. The total harmonic distortion is up to $95.9 \%$.

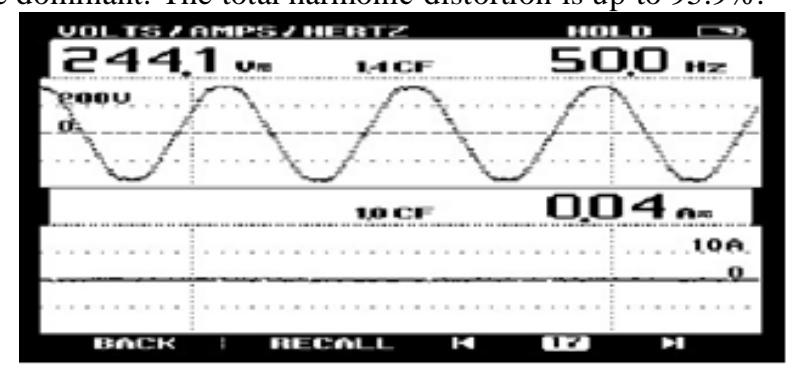

Fig 8. Supply voltage and current waveform of mobile charger (AC System)

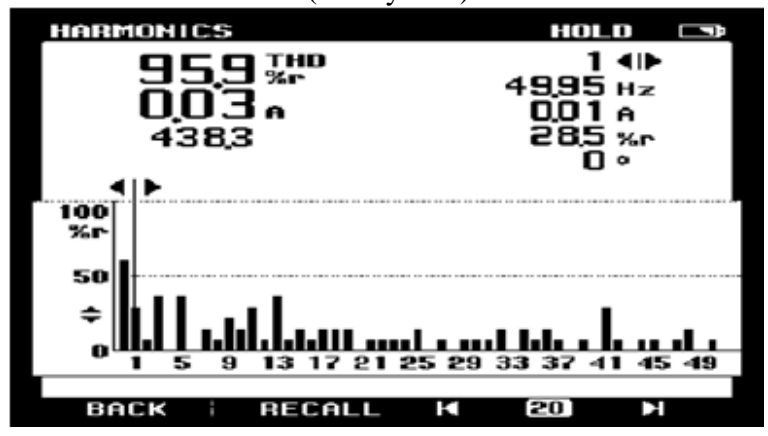

Fig. 9 Harmonic Distortion in mobile charger

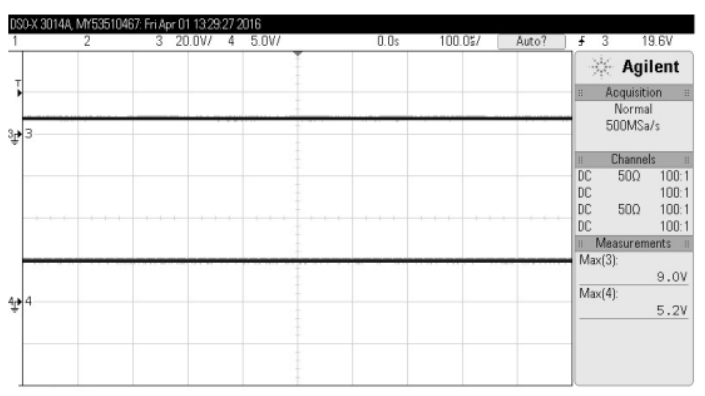

Fig 10. Supply voltage and current waveform for mobile charger (Standalone DC System)
The experimental results of supply voltage and load current for the same load as shown in Fig.10

\section{Laptop}

It can be observed that in each home there is an individual laptop for individual person. At most of the time laptops are always connected to the power supply. These process of charging create lots of harmonics in our system.



Fig. 11 Supply voltage and current waveform of Laptop (AC System)

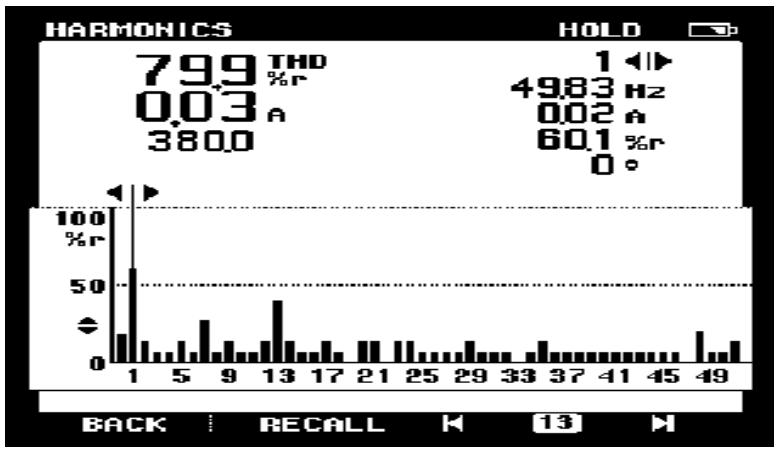

Fig .12 Harmonic Distortion in Laptop

It is noticed that the effect of harmonics and inter harmonics for device laptop are significant up to the order of $50^{\text {th }}$. It has all even and odd harmonics are present but $7^{\text {th }}$ and $13^{\text {th }}$ harmonics are dominant. The total harmonic distortion is up to $80 \%$. The experimental results are shown in Fig.13.

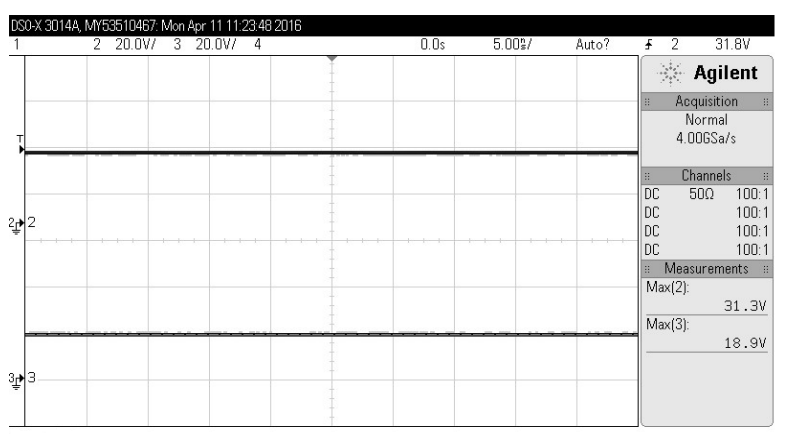

Fig .13 Supply voltage and current waveform for Laptop (Standalone DC System)

\section{Printer}

When only input is directly given to the printer the waveforms of supply voltage, current and THD are shown in Fig. 14 \& Fig. 15. 


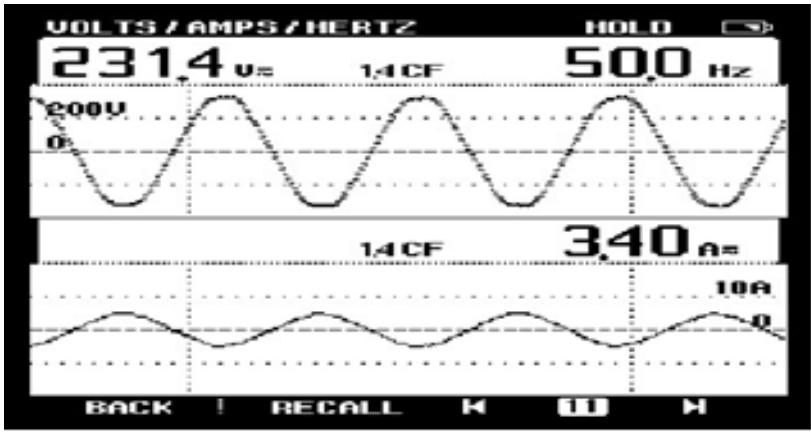

Fig. 14 Supply voltage and current waveform of Printer (AC System)

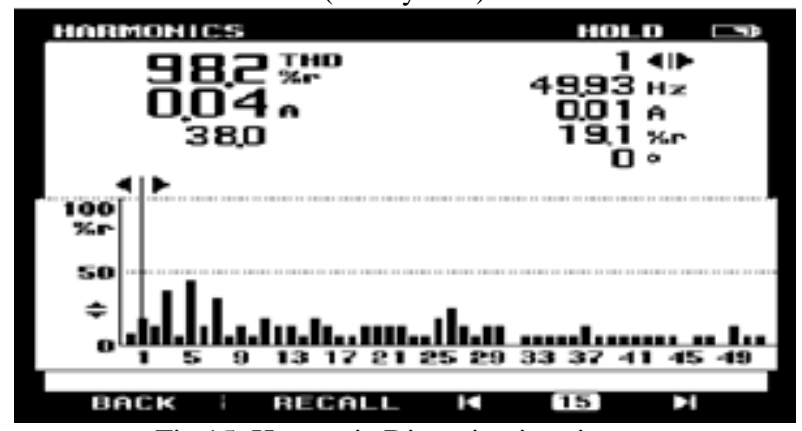

Fig 15. Harmonic Distortion in printer

It is noticed that the effect of harmonics and interharmonics for device printer are significant up to the order of $50^{\text {th }}$ and all even and odd harmonics are present. Mainly odd harmonics $3^{\text {rd }}, 5^{\text {th }}, 7^{\text {th }}, 9^{\text {th }}, 11^{\text {th }}$ up to $50^{\text {th }}$ are present. The total harmonic distortion is up to $98.2 \%$. The Simulation and experimental results of supply voltage and current of standalone DC system connected with the same load is shown in Fig. 16 \& Fig. 17.

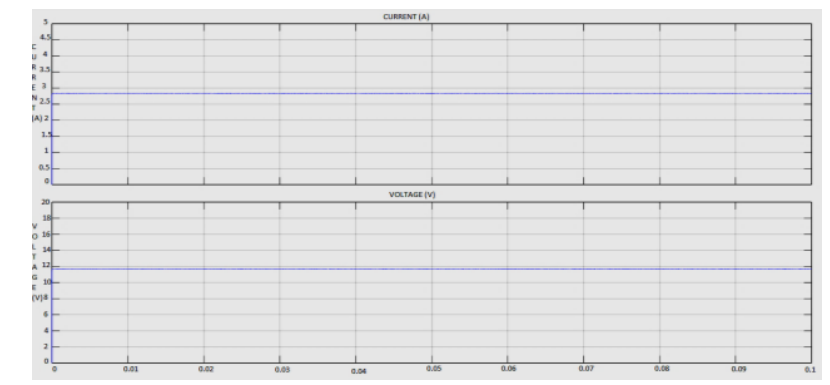

Fig. 16 Simulation Output Waveform of Load 2 ( Motor Load)

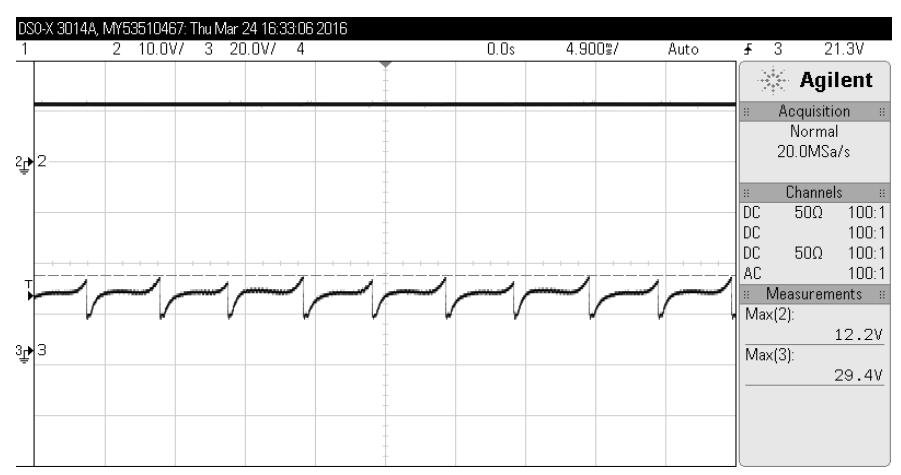

Fig. 17 Supply voltage and current waveform of Printer (Standalone DC System)

\section{CONCLUSION}

The power quality deterioration due to few residential loads has been discussed in this paper. If the number of such residential loads are increased in number, considerable amount of harmonic distortion produced which affect the power quality of the distribution system and overall grid. The networks can be equipped with filters to decrease the distortion, but such devices are highly expensive and are not widely used.

A standalone DC system comprising Photovoltaic (PV) arrays, and a secondary battery is presented in this paper. However, the results show that the power quality improvement (decrease in distortion) in aspect of harmonics and the power conversion losses can be greatly reduced with the absence of transformer and rectifier circuits. Besides, the cost of electricity produced from this system so as to determine its competitiveness with the conventional source of electricity is accountable and measurable. These type of systems can be implemented in future where fossil fuels demands are increasing day by day and use of non-conventional energy sources, especially PV is getting increased.

\section{REFERENCES}

[1] Sergey Yanchenko and Jan Meyer, "Harmonic Emission of household devices in presence of typical voltage distortion", pp. 1-6, IEEE,29 June to 1 July 2015.

[2] Lauri Kutt, Eero Saarijiarvi, Matti Lehtonen, Heigo Molder and Toomas Vinnal, "Harmonic load of residential distribution network - case study monitoring result", IEEE, pp.93-98, 2014.

[3] V. Becirovic, B. Nikolic, S. Hanjalie, M. Brkic, "Modeling a group of consumers in order to analyses power quality", pp. 1-7, 6-8 June, 2013.

[4] Rakesh Saxena, Karuna Nikum, "Comparative study of different residential illumination appliances based on power quality", pp. 1-5, 6-8 Dec 2012.

[5] Lj. Arsov, I. Ilazi, S. Mircevski, M. Cundeva-Blajer, A.Abazi, "Measurement of the influence of household power electronics on the power quality", 15 international power electronics and motion control conference, EPE-PEMC, pp.1-7, 4-6 Sept 2012.

[6] R.N. Bhargavi, "Power quality improvement using interline unified power quality conditioner", pp. 1-5, 8-11 May, 2011

[7] C.W. Liu, C.C. Luo, P.Y. Lin, G. C. Lu, W. C. Wu, J. I. Tsai, C. Y. Hsueh, "Develop a power quality measurement system integrated with HAN Home Energy Management System", pp. 1056-1510, 6-9 July 2011.

[8] H. A. Hejazi, Ali R. Araghi, Behrooz Vahidi, S. H. Hosseinian, M. Abedi, and Hamed Mohsenian-Rad, Member, IEEE, "Independent Distributed Generation Planning to Profit Both Utility and DG Investors" IEEE transactions on power systems, vol.28, no.2, may2013. http://dx.doi.org/10.1109/TPWRS.2012.2219325

[9] S.K. Khadem, M. Basu, M.F. Conlon, "Power Quality in Grid connected Renewable Energy Systems: Role of Custom Power Devices," International Conference on Renewable Energies and Power Quality, Granada(Spain), March 2010.

[10] J D Mondol, Y Yohanis, M Smyth, B Norton, "Long term performance analysis of a grid connected photovoltaic system in Northern Ireland". Energy conv \& mang, 2006, vol.47, pp.2925-2947.

[11] R Teodorescu, F Blaabjerg M Liserre, U Borup, "A New control structure for grid connected PV inverters with zero steady state error and selective harmonics compensation" in Proc. PESC2004, pp 1742-1747.

[12] X Yuan, W Merk, H Stemmler, J Allmeling, "Stationary frame Generalized integrators for Current control of Active power filters with zero steady-state error for current harmonics of concern under unbalanced and distorted operating conditions" IEEE Trans. On Ind. App., 2002, vol.38(2), pp.523-532. http://dx.doi.org/10.1109/28.993175

[13] A.Ghosh and G Ledwich, "Power Quality enhancement using custom power devices",Kluwer Academic, 2002.

http://dx.doi.org/10.1007/978-1-4615-1153-3 